\title{
ESTUDO FENOLÓGICO EM TRÊS FASES SUCESSIONAIS DE UMA FLORESTA ESTACIONAL DECIDUAL NO MUNICÍPIO DE SANTA TEREZA, RS, BRASIL ${ }^{1}$
}

\author{
Cáren Andreis ${ }^{2}$, Solon Jonas Longhi ${ }^{3}$, Eleandro José Brun ${ }^{4}$, Júlio César Wojciechowski ${ }^{5}$, Antônio \\ Augusto Machado ${ }^{5}$, Sandro Vaccaro ${ }^{6}$ e Christian Zago Cassal ${ }^{7}$
}

\begin{abstract}
RESUMO - O presente estudo foi realizado em 40 parcelas de área fixa pertencentes a três estágios sucessionais, denominados: Capoeirão, Floresta Secundária e Floresta Madura, em uma Floresta Estacional Decidual no município de Santa Tereza, RS. Foram realizadas observações fenológicas quinzenais em 53 espécies arbóreas, numa média de 8,4 indivíduos por espécie, durante o período de 16 de novembro de 2001 a 10 de novembro de 2002. As fenofases observadas foram floração, frutificação e mudança foliar. Os resultados indicaram que a atividade reprodutiva manteve uma porcentagem relativamente baixa nos três estágios sucessionais durante o período observado, com tendências em ser menor durante a estação de inverno. A quantidade total de folhas na árvore, não se distinguindo estágio sucessional, diminuiu de aproximadamente $85 \%$ no período de maior atividade vegetativa para até $35 \%$ no inverno, período de repouso, sendo a Floresta Madura a subsere, que manteve os maiores porcentuais de folhas durante o período estudado.
\end{abstract}

Palavras-chave: Fenofases, sucessão florestal e Floresta Estacional Decidual.

\section{PHENOLOGY STUDY IN THREE SUCCESSIONAL STAGES OF A SEASONAL DECIDUOUS FOREST IN SANTA TEREZA, RS, BRAZIL}

\begin{abstract}
The present study was accomplished in forty permanent plots belonging to three forest successional stages, denominated: Brush Forest, Secondary Forest and Mature Forest, in a seasonal deciduous forest in the municipal district of Santa Tereza, RS, Brazil. Phenologic observations were accomplished fortnightly for 53 arboreal species, in an average of 8,4 individuals per species, during the period of November 2001 to November 2002. The stages observed were flowering, fruiting and foliage change. The results indicate that the reproductive activity remained relatively low for three successional stages during the observed period, with a tendency to be even lower during winter. The total amount of leaves on the trees, regardless of the successional stage, decreased from approximately $85 \%$, in the period of higher vegetative activity, to $35 \%$ in the winter, resting season. The Mature Forest maintained the largest percentage of leaves during the studied period.
\end{abstract}

Key words: Phenology stages, forest succession and Seasonal Deciduous Forest.

\footnotetext{
${ }^{1}$ Recebido em 07.11.2003 e aceito para publicação em 25.11.2004.

${ }^{2}$ Programa de Pós-Graduação em Engenharia Agrícola: Departamento de Engenharia Rural da UFSM. Santa Maria, RS. E-mail:<ca.floresta@bol.com.br>.

${ }^{3}$ Departamento de Ciências Florestais da UFSM. 97105-900 Santa Maria, RS. E-mail: <longhiso@ ccr.ufsm.br>.

${ }^{4}$ Departamento de Ciências Florestais da UFSM. 97105-900 Santa Maria, RS.

${ }^{5}$ Programa de Pós-Graduação em Engenharia Florestal - CCR - UFSM. Santa Maria, RS.

${ }^{6}$ Eng. Florestal. Dr.: Rua Refatti, 119 - Bairro Maria Goretti. 95700-000 Bento Gonçalves, RS.

${ }^{7}$ Curso de Engenharia Florestal da UFSM.
} 


\section{INTRODUÇÃO}

A observação das fenofases das espécies é uma prática que vem sendo realizada desde os primórdios das civilizações, quando o homem, necessitando de alimento, buscou diferenciar quais as espécies poderiam ser utilizadas em sua alimentação nos diferentes períodos do ano. Os estudos de fenologia, segundo Abbe apud Gonzalez (1988), tiveram início há aproximadamente 1.000 anos, na China e em Roma, onde foram encontrados os primeiros registros de observações e calendários fenológicos. Esse autor citou que o termo "fenologia" passou a ser usado a partir da segunda metade do século XIX e foi proposto pelo botânico belga Charles Morren.

A fenologia é uma ciência que identifica os fenômenos de floração, frutificação, brotamento e queda de folhas, nas suas mais diferentes e intensas fases, objetivando o conhecimento do ciclo anual das espécies em estudo, o qual está diretamente relacionado às condições climáticas e ao caráter adaptativo de cada espécie em sua área de dispersão.

Na Região Sul do Brasil, informações acerca da fenologia de espécies florestais nativas são escassas. Já na região tropical brasileira vários trabalhos foram realizados reportando mudanças de fenofases conforme períodos secos e chuvosos, como os de Morellato et al. (1990), Morellato (1991) e Costa et al. (1992). No entanto, é difícil encontrar na literatura brasileira pesquisas que relacionem essas mudanças com períodos frios e períodos quentes, tornando-se necessários estudos dessa natureza.

O estudo fenológico de populações florestais da Região Sul do Brasil trouxe informações e subsídios a programas de recuperação florestal, ou qualquer outro programa que necessite de sementes de espécies florestais nativas, bem como a outros projetos que visem ao entendimento de populações vegetais, indicando qual o período de frutificação, floração, brotamento e queda de folhas de cada espécie individual e quais os picos de ocorrência de cada uma das fenofases citadas, para a população ou comunidade, no decorrer do ano. Dessa forma, o objetivo deste trabalho foi estudar as fenofases de floração, frutificação e mudança foliar em três estágios sucessionais de uma Floresta Estacional Decidual, no município de Santa Tereza, RS.

\section{MATERIAL E MÉTODOS}

O presente projeto de pesquisa foi desenvolvido no município de Santa Tereza, região nordeste do Estado do Rio Grande do Sul. A zona urbana de Santa Tereza situa-se em terreno plano a suavemente ondulado, a cerca de $100 \mathrm{~m}$ de altitude. A cidade é rodeada por elevações montanhosas que atingem em torno de 500 a $600 \mathrm{~m}$ de altitude. As vertentes dos morros são cobertas por vegetação pertencente à Floresta Estacional Decidual, em vários estágios sucessionais, e somente nos topos dos morros, em altitudes acima de $500 \mathrm{~m}$, observouse infiltração da Floresta Ombrófila Mista, com a ocorrência nítida de Araucaria angustifolia.

O estudo foi realizado em três fases sucessionais de porte arbóreo da Floresta Estacional Decidual, utilizando-se as mesmas unidades amostrais trabalhadas por Vaccaro (1997) para a realização de um estudo fitossociológico. O referido autor denominou as subseres de "Capoeirão", "Floresta Secundária" e "Floresta Madura".

O clima local é do tipo $C f a$, segundo a classificação de Köppen. Os solos são derivados de Rochas Efusivas Básicas da Formação Serra Geral, apresentando basalto como substrato.

Em cada estágio sucessional, encontravam-se instaladas 10 parcelas permanentes de $10 \times 20 \mathrm{~m}$, distribuídas de forma sistemática, amostrando todas as árvores com CAP superior ou igual a $10 \mathrm{~cm}$, independentemente de sua condição sanitária ou fitossociológica. Neste estudo, porém, foram considerados somente os $2 \mathrm{~m}$ centrais de cada unidade amostral original, ou seja, $2 \mathrm{~m}$ de largura por $20 \mathrm{~m}$ de comprimento $\left(40 \mathrm{~m}^{2}\right)$, totalizando $400 \mathrm{~m}^{2}$ de área amostral nas subseres Capoeirão e Floresta Secundária. Na subsere Floresta Madura, devido à pequena freqüência de indivíduos, foram consideradas mais 10 parcelas de mesmo tamanho que as anteriores, totalizando $800 \mathrm{~m}^{2}$ de área amostral. A área amostral total era de $1.600 \mathrm{~m}^{2}$.

Os dados fenológicos foram coletados em 53 espécies, numa média de 8,4 indivíduos por espécie, num total de 416. A distribuição das espécies nos estágios sucessionais ficou assim definida:

- Capoeirão = 22 espécies, com média de 6,5 indivíduos por espécie, totalizando 144 exemplares.

- Floresta Secundária $=28$ espécies, com média de 3,9 indivíduos por espécie, totalizando 110 exemplares. 
- Floresta Madura = 25 espécies, com média de 6,5 indivíduos por espécie, totalizando 162 exemplares.

Foi realizado o acompanhamento fenológico quinzenal, iniciado em 16 de novembro de 2001 e finalizado em 10 de novembro de 2002. Os eventos fenológicos acompanhados foram: floração, frutificação e mudança foliar, sendo cada um desses caracterizados da seguinte forma:

Floração = evento qualificado conforme sua progressão em três períodos: botões florais, floração adiantada ou árvore totalmente florida e floração terminada ou terminando.

Frutificação = evento também qualificado em três períodos: frutos novos, frutos maduros e frutos caindo ou sementes dispersas.

Mudança foliar = observaram-se os períodos de brotação, folhas novas e folhas adultas e, ou, maduras. Nessa fenofase, os eventos citados foram, além de qualificados, quantificados em intervalos de porcentagem de $25 \%$, conforme critérios visuais.

Para as fenofases de floração e frutificação foram confeccionadas tabelas demonstrando o período de floração e de frutificação das espécies que apresentaram ocorrência dos eventos citados, em cada subsere.

Para a fenofase "mudança foliar" foram confeccionados gráficos indicando a variação da quantidade total de folhas em todas as árvores amostradas e cada subsere, separadamente.

\section{RESULTADOS E DISCUSSÕES}

A atividade reprodutiva apresentou porcentagem relativamente baixa nas três subseres estudadas, tanto nas espécies quanto nos indivíduos.

Das 53 espécies estudadas, apenas 24 floresceram no decorrer do estudo. A menor quantidade de espécies que apresentaram o evento floração foi observada na Floresta Secundária (Quadro 2), onde, das 28 espécies estudadas, apenas nove floriram, ou seja, $32 \%$ das espécies. No Capoeirão (Quadro 1), das 22 espécies observadas, 11 floresceram (50\%). Já, na Floresta Madura (Quadro 3), 14 das 25 espécies estudadas floresceram durante o período estudado, representando uma porcentagem de floração de $56 \%$.

A floração apresentou um padrão sazonal no nível de espécie, diretamente vinculada ao aumento de temperatura entre os meses de julho e outubro. Das 24 espécies em que foi observado floração, $10(41,7 \%)$ floresceram entre final de julho e outubro, cinco espécies $(20,8 \%)$ estavam florindo no início da coleta dos dados, em novembro. Padrão semelhante foi relatado por Alberti (2002), em estudo sobre uma Floresta Estacional Decidual localizada em Santa Maria, Rio Grande do Sul.

Nos meses de maio e junho, período marcado por temperaturas mais baixas, apenas duas espécies floresceram, sendo elas: Cupania vernalis Cambess. na Floresta Secundária e Alchornea triplinervia (Spreng.) Müll. Arg. na Floresta Madura.

Para frutificação, das 53 espécies, apenas 17 frutificaram. Também foi na Floresta Secundária onde se observou a menor quantidade de espécies apresentando o evento, numa porcentagem de $25 \%$, seguida pelo Capoeirão, onde $32 \%$ das espécies frutificaram e, por último, a Floresta Madura, com 44\% das espécies.

Das espécies que floresceram, não foi observado frutificação em Machaerium sp., Boehmeria caudata Sw., Lonchocarpus campestris Mart. ex Benth., Myrocarpus frondosus M. Allemão, Inga semialata (Vell.) Mart., Allophylus guaraniticus (A. St-Hil.) Radlk., Solanum pseudoquina A. St-Hil., Myrsine umbellata Mart., Pisonia ambigua Heimerl e Cabralea canjerana (Vell.) Mart. Já Cedrella fissilis Vell., Pilocarpus pennatifolius Lem. e Daphnopsis racemosa Griseb. frutificaram, mas, durante o período estudado, não foi observado floração.

O padrão de dispersão predominante nas três subseres foi o zoocórico, sendo representado por $59 \%$ das espécies do Capoeirão, $71 \%$ na Floresta Secundária e $76 \%$ na Floresta Madura. As porcentagens de espécies de padrão de dispersão anemocórico foram de 36, 25 e 20, respectivamente, nas três subseres. Já as espécies autocóricas ficaram representadas por 5, 4 e 4\%, respectivamente, nas três subseres.

A predominância de espécies zoocóricas também foi observada por Morellato (1991), a qual registrou valores de $57 \%$ dessas espécies, contra $27 \%$ de anemocóricas e $15 \%$ de autocóricas das árvores e arbustos da Reserva Municipal de Santa Genebra,

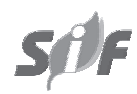

R. Árvore, Viçosa-MG, v.29, n.1, p.55-63, 2005 
Campinas, SP. Segundo tal autora, essa proporção parece aumentar, principalmente no estrato superior, à medida que as florestas se tornam mais úmidas e menos sujeitas a uma forte estacionalidade climática. Plantas dispersas pelo vento seriam mais comuns em florestas secas e estágios sucessionais iniciais.

Alberti (2002) também observou essa predominância de espécies zoocóricas em seu estudo sobre a fenologia de dois morros, em Santa Maria, RS. No entanto, tal predominância diminuiu de $75 \%$ de espécies zoocóricas no Morro do Cerrito para $60 \%$ de espécies zoocóricas no Morro Tabor, o qual se recuperava de intervenções mais recentes.

Os padrões de floração e frutificação, independentemente do estágio sucessional, foram semelhantes nas diferentes espécies, ocorrendo coincidência dos eventos reprodutivos para uma mesma espécie amostrada em duas ou três subseres, em quase todas as espécies que apresentaram esses eventos (Quadros 1, 2 e 3).

Quadro 1 - Fenologia da floração e da frutificação das espécies na subsere Capoeirão, em Santa Tereza, RS Table 1 - Flowering and fructification phenology of species to the Brush Forest, Santa Tereza, RS, Brazil

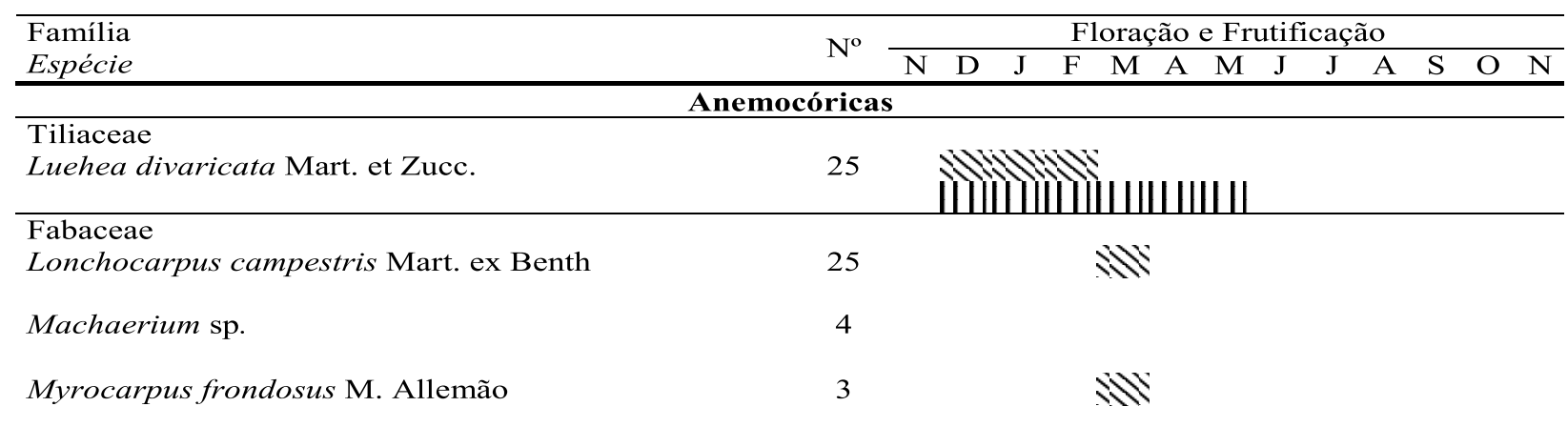

Autocóricas

Caesalpinaceae

12

Bauhinia forficata Link

Zoocóricas

Sapindaceae

Allophylus edulis (A. St-Hill. et al.) Radlk.

Cupania vernalis Cambess.

16 || ||||||

8

Euphorbiaceae

Sapium glandulatum (Vell.) Pax.

$1 \$$

\begin{tabular}{lll}
\hline $\begin{array}{l}\text { Lauraceae } \\
\text { Nectandra megapotamica (Spreng.) Mez. }\end{array}$ & 3 & \\
\hline $\begin{array}{l}\text { Meliaceae } \\
\text { Trichilia elegans A. Juss. }\end{array}$ & 4 & \\
\hline $\begin{array}{l}\text { Flacourtiaceae } \\
\text { Casearia silvestris Sw. }\end{array}$ & 8 & \\
\hline $\begin{array}{l}\text { Solanaceae } \\
\text { Solanum pseudoquina A. St-Hil. }\end{array}$ & 2 &
\end{tabular}

$\mathrm{N}^{\mathrm{o}}=$ número de indivíduos amostrados.

Slì Floração $\quad$ ||l| Frutificação

R. Árvore, Viçosa-MG, v.29, n.1, p.55-63, 2005 
Quadro 2 - Fenologia da floração e da frutificação das espécies na subsere Floresta Secundária, em Santa Tereza, RS Table 2 - Flowering and fructification phenology of species to the Secondary Forest, Santa Tereza, RS, Brazil

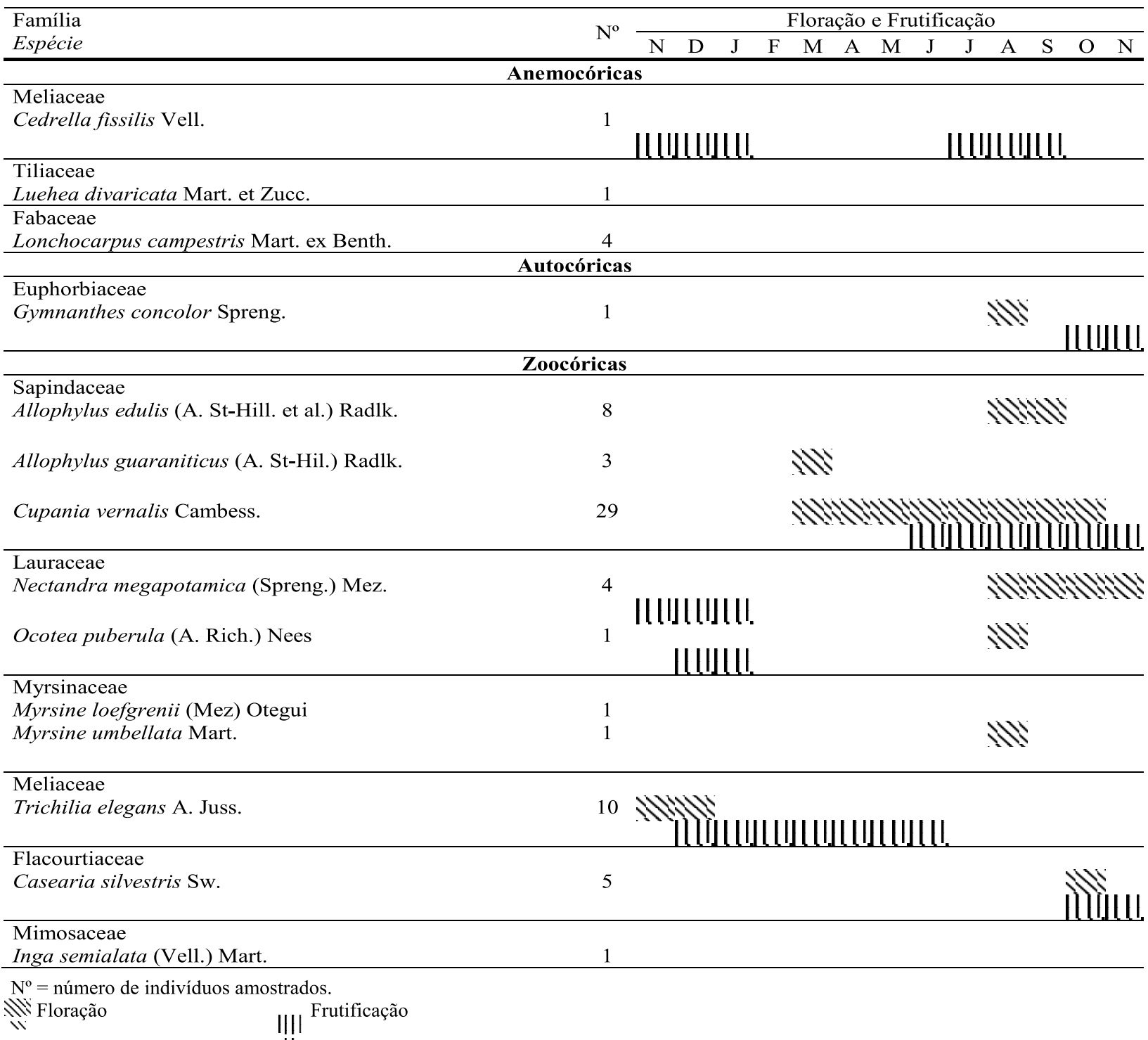

As espécies estudadas em que não foram observadas floração e frutificação encontram-se listadas no Quadro 4. Os baixos porcentuais de atividade reprodutiva em nível de espécie e de indivíduo podem ser explicados pela aleatoriedade de seleção dos indivíduos, selecionados conforme sua aparição na parcela, não se considerando o estado sanitário ou social. Muitos dos indivíduos encontravam-se suprimidos, quebrados e, ou, atacados por agentes biológicos e não foram excluídos do estudo, com a ressalva de que tais valores porcentuais representam a população como um todo e não a porcentagem de atividade reprodutiva de indivíduos selecionados.

A estacionalidade da floresta em questão pode ser confirmada quando se visualiza a Figura 1, na qual se observa que a variação da quantidade de folhas ao longo do período estudado é devida às mudanças climáticas, caracterizadas por duas estações bem definidas: inverno e verão. Tal fato também foi relatado por Longhi (1997) e Alberti (2002). 
Quadro 3 - Fenologia da floração e da frutificação das espécies na subsere Floresta Madura, em Santa Tereza, RS Table 3 -Flowering and fructification phenology of species to the Mature Forest, Santa Tereza, RS, Brazil

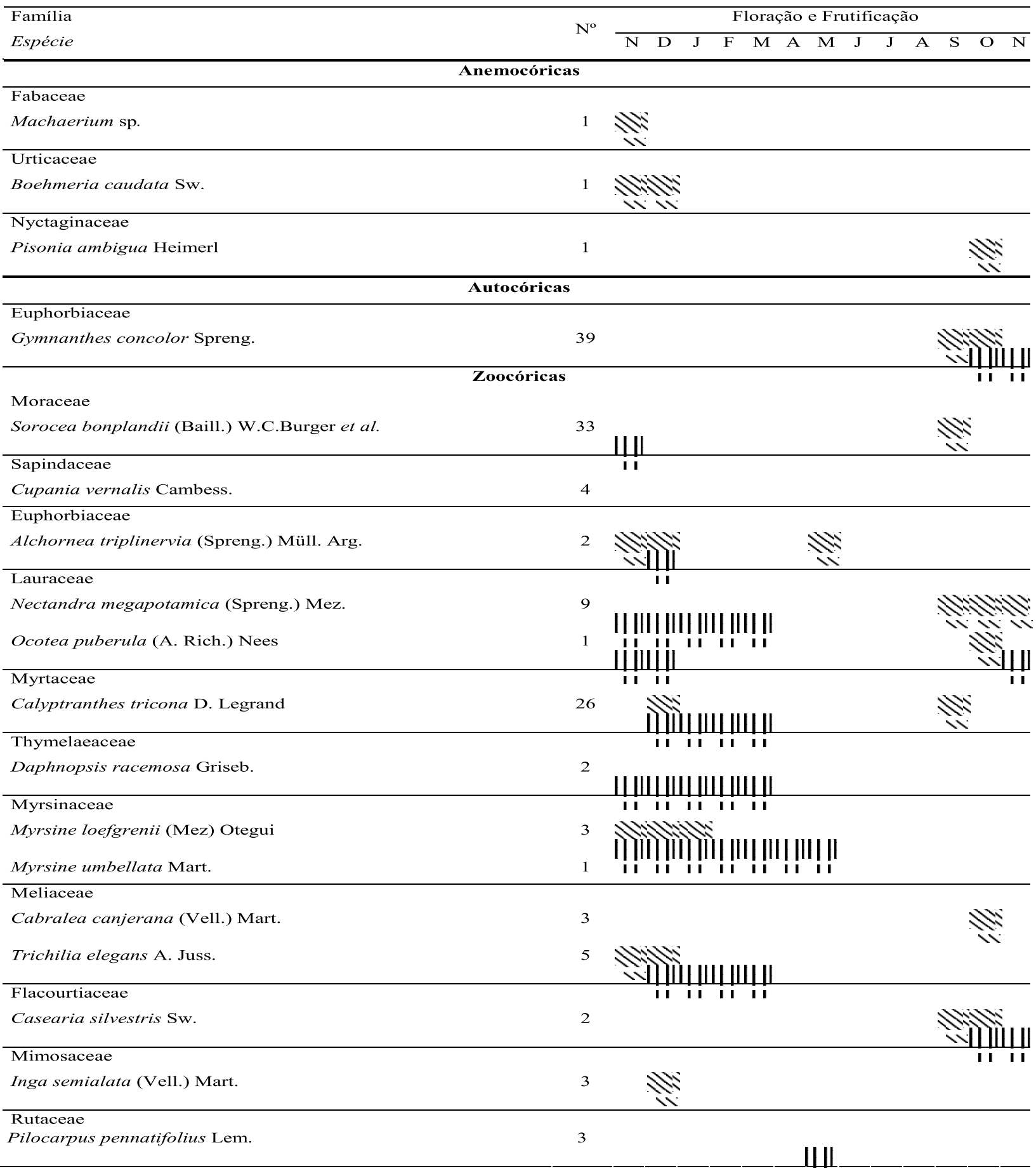

$\mathrm{N}^{\mathrm{o}}=$ número de indivíduos amostrados.

Nin Floração $\quad$ III Frutificação

R. Árvore, Viçosa-MG, v.29, n.1, p.55-63, 2005 
Quadro 4 - Relação das espécies em que não foram observadas floração e frutificação e dos respectivos números de indivíduos observados por espécie nos estágios sucessionais Capoeirão, Floresta Secundária e Floresta Madura

Table 4 -Relation of the species for which flowering and fructification were not observed and the respective number of individuals observed for species in the succesional stages Brush Forest, Secondary Forest and Mature Forest

\begin{tabular}{|c|c|c|c|c|c|}
\hline \multirow[t]{2}{*}{ Família } & \multirow[t]{2}{*}{ Espécie } & \multirow[t]{2}{*}{ PD } & \multicolumn{3}{|c|}{$\mathrm{N}^{\circ}$} \\
\hline & & & $\mathrm{C}$ & FS & FM \\
\hline Apocynaceae & Aspidosperma australe Müller & A & 6 & 0 & 0 \\
\hline Aquifoliaceae & Ilex brevicuspis Reissek & $\mathrm{Z}$ & 2 & 0 & 0 \\
\hline Bignoniaceae & Tecoma stans $($ L.) Kunth & A & 1 & 0 & 0 \\
\hline Caesalpinaceae & Apuleia leiocarpa (Vogel) J. F. Macbr. & A & 0 & 1 & 4 \\
\hline Celastraceae & Maytenus aquifolia Mart. & $\mathrm{Z}$ & 0 & 2 & 0 \\
\hline Celastraceae & Maytenus ilicifolia Mart. ex Reissek & $\mathrm{Z}$ & 1 & 0 & 0 \\
\hline Ebenaceae & Maba inconstans (Jacq.) Griseb. & $\mathrm{Z}$ & 10 & 0 & 0 \\
\hline Elaeocarpaceae & Sloanea monosperma Vell. & $\mathrm{Z}$ & 0 & 1 & 0 \\
\hline Fabaceae & Lonchocarpus nitidus (Vogel) Benth. & A & 0 & 2 & 0 \\
\hline Fabaceae & Machaerium stipitatum Vogel & A & 4 & 7 & 0 \\
\hline Flacourtiaceae & Banara parviflora (A. Gray) Benth. & $\mathrm{Z}$ & 0 & 1 & 0 \\
\hline Flacourtiaceae & Banara tomentosa $\mathrm{Clos}$ & $\mathrm{Z}$ & 0 & 2 & 0 \\
\hline Flacourtiaceae & Casearia decandra Jacq. & $\mathrm{Z}$ & 1 & 0 & 0 \\
\hline Flacourtiaceae & Xylosma pseudosalzmanii Sleumer & $\mathrm{Z}$ & 0 & 1 & 0 \\
\hline Icacinaceae & Citronella paniculata (Mart.) Howard & $\mathrm{Z}$ & 0 & 4 & 0 \\
\hline Meliaceae & Trichilia catigua A. Juss. & $\mathrm{Z}$ & 0 & 10 & 7 \\
\hline Mimosaceae & Parapiptadenia rigida (Benth.) Brenan & A & 3 & 3 & 1 \\
\hline Myrtaceae & Campomanesia xanthocarpa O. Berg & $\mathrm{Z}$ & 0 & 0 & 1 \\
\hline Myrtaceae & Eugenia involucrata DC. & $\mathrm{Z}$ & 3 & 0 & 0 \\
\hline Myrtaceae & Eugenia ramboi D. Legrand & $\mathrm{Z}$ & 0 & 0 & 3 \\
\hline Myrtaceae & Eugenia rostrifolia D. Legrand & $\mathrm{Z}$ & 0 & 0 & 2 \\
\hline Myrtaceae & Myrcianthes pungens $(\mathrm{O}$. Berg) D. Legrand & $\mathrm{Z}$ & 0 & 1 & 0 \\
\hline Rubiaceae & Randia armata $(\mathrm{Sw}.) \mathrm{DC}$. & $\mathrm{Z}$ & 0 & 1 & 0 \\
\hline Sapindaceae & Matayba elaeagnoides Radlk. & $\mathrm{Z}$ & 0 & 4 & 0 \\
\hline Simaroubaceae & Picrasma crenata (Vell.) Engl. & $\mathrm{Z}$ & 0 & 0 & 1 \\
\hline Solanaceae & Solanum sanctae-catharinae Dunal & $\mathrm{Z}$ & 2 & 0 & 0 \\
\hline
\end{tabular}

$\mathrm{N}^{\circ}=$ número de indivíduos por subsere, $\mathrm{PD}=$ padrão de dispersão, $\mathrm{A}=$ anemocórica, $\mathrm{Z}=$ zoocórica, $\mathrm{C}=\mathrm{capoeirão}, \mathrm{FS}=\mathrm{floresta}$ secundária $\mathrm{e}$ $\mathrm{FM}=$ floresta madura.

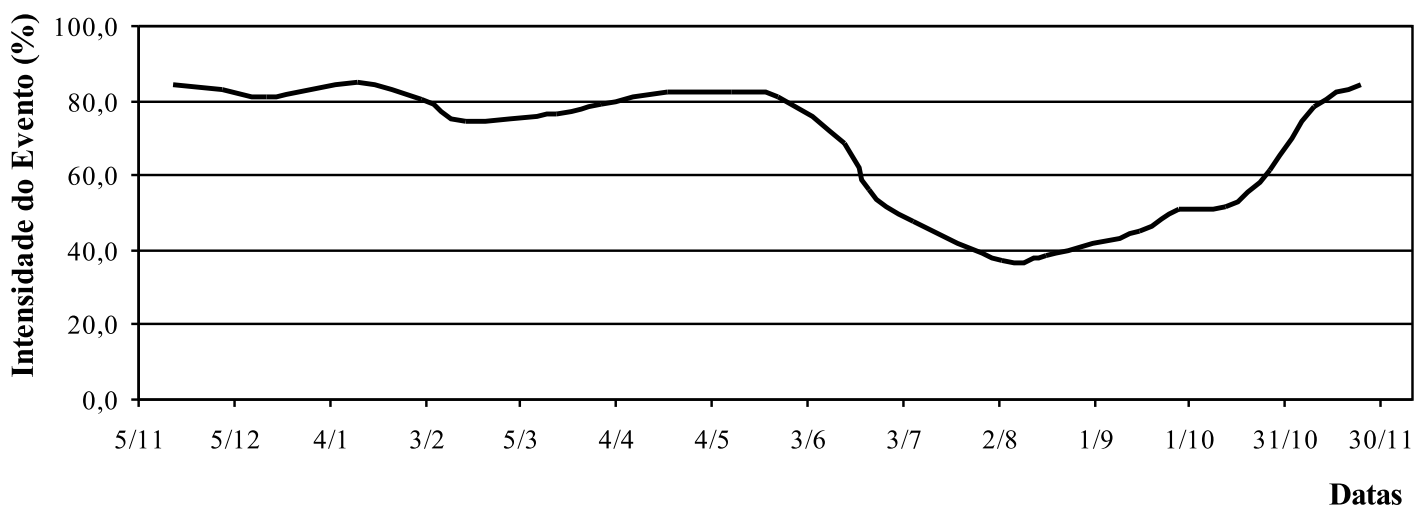

Figura 1 - Variação da quantidade total de folhas, quinzenalmente, em todas as árvores estudadas.

Figure 1 -Bi-monthly changes of the total leaf amount, for all studied trees. 
Também se confirma a denominação decidual segundo a conceituação de Klein (1983), o qual tipifica uma floresta como tal quando esta perde mais de $50 \%$ de suas folhas. Na Figura 1, pode-se observar que a quantidade total de folhas, não se distinguindo estágio sucessional, diminui aproximadamente $85 \%$ no período de maior atividade vegetativa, para até $35 \%$ no inverno, período de repouso.

Observa-se também tal fato na análise das subseres separadamente (Figura 2). A Floresta Madura foi a que manteve os maiores porcentuais de folhas ao longo do período estudado, seguida pela Floresta Secundária e, por último, pelo Capoeirão. A perda de folhas é de 50,6\% na Floresta Madura, 62,3\% na Floresta Secundária e $53,5 \%$ no Capoeirão.

A maior quantidade de folhas, independentemente do estágio sucessional, foi observada entre os meses de novembro de 2001 e junho de 2002 , com uma ligeira queda no mês de fevereiro (Figura 2), possivelmente devido a algum parâmetro climático desfavorável no momento. A partir do mês de junho de 2002 ocorreu uma queda abrupta nos índices de quantidade total de folhas nas três subseres até o mês de agosto. A partir de tal mês ocorreu aumento na quantidade total de folhas até o mês de novembro de 2002, quando esse índice atingiu valores semelhantes àqueles do período anterior.

A variação da quantidade de folhas ao longo do ano apresenta uma correlação positiva com a deposição das folhas da serapilheira, quando se comparam os dados obtidos com os observados por Brun et al. (2001), em estudo realizado na mesma área, entre os anos de 1995 e 1997 . Neste trabalho, foi observado maior deposição de folhas e de serapilheira total nos meses de outubro, novembro e fevereiro, para a subsere Capoeirão. Na Floresta Secundária, os meses em que foi observado maior quantidade de folhas e de serapilheira total coincidiram com os do Capoeirão, mas com amplitudes maiores, além de uma produção elevada no mês de dezembro de 1996. Já a Floresta Madura apresentou dois períodos nitidamente diferenciados, com elevadas deposições entre os meses de setembro e fevereiro, no primeiro período (primavera/verão), e uma queda abrupta no total mensal de serapilheira entre os meses de março e agosto, no segundo período (outono/ inverno).

Pode-se inferir, dessa forma, que essa correlação positiva indicando maior deposição de serapilheira na primavera, juntamente com o aumento da quantidade de folhas observadas na árvore nesse mesmo período, deve-se à emissão de brotos e folhas novos e à perda das folhas velhas restantes do ciclo anterior. A maior deposição de serapilheira nesse período é explicada por Brun et al. (2001) pelo maior índice de chuvas, assim como o vento e o aumento da temperatura durante a primavera. Tais fatores ambientais, além de contribuir para a queda de folhas velhas, contribuem para a emissão de novas folhas, que vão perdurar até o final do próximo ciclo, no término do inverno.

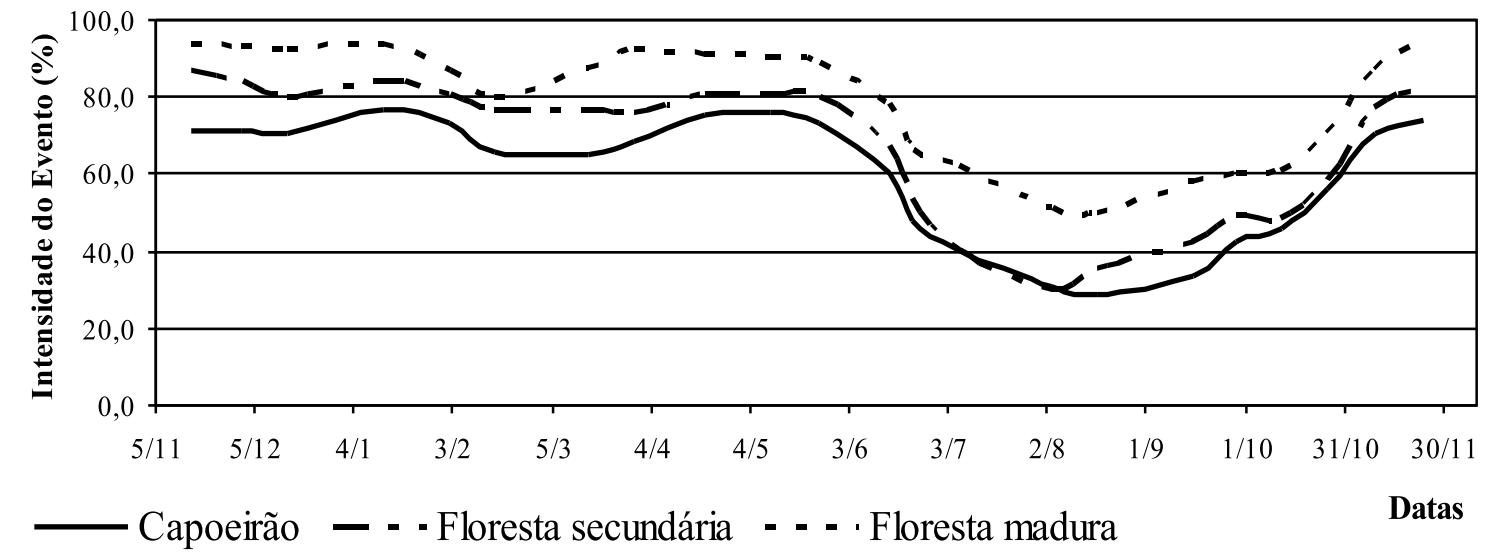

Figura 2 - Variação da quantidade total de folhas, quinzenalmente, em cada subsere.

Figure 2 - Bi-monthly changes of the total leaf amount, in each forest area.

R. Árvore, Viçosa-MG, v.29, n.1, p.55-63, 2005 


\section{CONCLUSÕES}

A atividade reprodutiva manteve-se em porcentagem relativamente baixa nas três subseres estudadas, tanto para espécies quanto para indivíduos.

Das 53 espécies estudadas, apenas 24 floresceram no decorrer do estudo. A floração apresentou um padrão sazonal no nível de espécie, diretamente vinculada ao aumento de temperatura entre os meses de julho e outubro.

Para frutificação, das 53 espécies, apenas 17 frutificaram. O padrão de dispersão predominante nas três subseres foi o zoocórico, sendo representado por $59 \%$ das espécies do Capoeirão, $71 \%$ da Floresta Secundária e $76 \%$ da Floresta Madura.

A quantidade total de folhas, não se distinguindo estágio sucessional, diminui de aproximadamente $85 \%$ no período de maior atividade vegetativa até $35 \%$ no inverno, período de repouso.

A Floresta Madura foi a que manteve os maiores porcentuais de folhas ao longo do período estudado. A perda de folhas é de 50,6\% na Floresta Madura, 62,3\% na Floresta Secundária e 53,5\% no Capoeirão.

Seria interessante acompanhar mais alguns anos para se poder confeccionar o calendário fenológico das espécies.

\section{REFERÊNCIAS BIBLIOGRÁFICAS}

ALBERTI, L. F. Fenologia de uma Comunidade Arbórea em Santa Maria - RS. 2002, 144f. Dissertação (Mestrado em Engenharia Florestal). Universidade Federal de Santa Maria, Santa Maria, 2002.

BRUN, E. J.et al. Relação entre a produção de serapilheira e variáveis meteorológicas em três fases sucessionais de uma Floresta Estacional Decidual no Rio Grande do Sul. Revista Brasileira de Agrometeorologia, v.9, n.2, p.277-285, 2001.
COSTA, M. L. M. N.; PEREIRA, T. S.; ANDRADE, A. C. S. Fenologia de algumas espécies de Mata Atlântica, Reserva Biológica de Macaé de Cima (Estudo preliminar). In: CONGRESSO NACIONAL SOBRE ESSÊNCIAS NATIVAS, 2., 1992, São Paulo. Revista do Instituto Florestal, v.4, p.226-232, 1992a (Edição Especial).

GONZALEZ, M. A. B. Consideraciones metodológicas para estudios fenológicos en bosques templados de coníferas. Ciência Forestal, v.13, n.64, julho/dezembro, 1988.

KLEIN, R. M. Aspectos fitofisionômicos da Floresta Estacional da Fralda da Serra Geral (RS). In.: CONGRESSO NACIONAL DE BOTÂNICA, 34., 1983, Porto Alegre, Anais... Porto Alegre: 1983, 2v., v.1, p.73-110.

LONGHI, S. J. Fenologia de algumas espécies florestais e ornamentais. Ciência Rural, v.14. n.3-4, p.231-240, 1984.

MORELLATO, L. C. P. et al. Estudo comparativo da fenologia de espécies arbóreas de floresta de altitude na Serra do Japi, Jundiaí, São Paulo.

Revista Brasileira de Biologia, v.1, n.50, p.85-98, 1990.

MORELlato, L. C. P. Estudo da fenologia de árvores, arbustos e lianas de uma Floresta Semidecidual no Sudeste do Brasil. 1991. 173f. Tese (Doutorado em Ecologia) - Universidade de Campinas, Campinas, 1991.

VACCARO, S. Caracterização

fitossociológica de três fases

sucessionais de uma Floresta Estacional Decidual, no município de Santa Tereza - RS. 1997. 92f. Dissertação (Mestrado em Engenharia Florestal) Universidade Federal de Santa Maria, Santa Maria, 1997. 
